\title{
Health care Providers practice toward Patient Safety in El-Ebor family health centers, Egypt
}

\author{
Hala M Shaheen*, Omima A Mahros**, Nagwa N Hegazy*, Shereen S Salem * \\ *Family Medicine, department ** community Medicine department Menoufia University \\ Received: 1-12-2015, Accepted :12- 1-2016
}

\begin{abstract}
Background and purpose: Safety is an area of inquiry that emphasizes the identification of risk, reporting, analysis and the prevention of unintended or potential harm associated with healthcare. According to WHO International Classification for Patient Safety, it is defined as: an event or circumstance which could have resulted in unnecessary harm to a patient. Objectives: Identify the frequency of patient safety errors among health care providers (HCP) and risk factors allied with error. Methods: A descriptive cross sectional study was conducted in El-Ebor family health centers, Qalyubia Governorate, Egypt. All the health care providers (172) were recruited for the study .Medical group was 123(family physicians, dentists and pharmacist) and Paramedical group 49(nurses, social workers and chemists). The participants' practice regarding patient safety was assessed using an observational checklist adopted from the Ministry of Health and Population (MOHP) checklist after modification. The checklist included items about: patient identification, Laboratory \& pharmacy measures, Infection control measures, Provider compliance and Safety climate. According to the observational checklist, participants were classified as having accepted or non- accepted practice (practice medical errors). Results: This study showed that nearly half of the health care providers were less than 30 years old (51.7\%). The majority of them were females (91\%). About $71 \%$ of the studied group had non-accepted practice (medical errors) regarding patient safety. Nearly $33 \%$ of the medical personnel had an accepted practice while $81.6 \%$ of the paramedical had non-accepted practice. There was statistically significant difference in the accepted practice concerning the patient's safety that interrelated to infection control and patient identification among paramedical group than medical category group. Group having experience less than five years showed more accepted practice regarding providers' compliance to guideline and policy than the other group Conclusion: Paramedical staff had an accepted safety practice regarding patient identification and infection control compared to medical staff. Provider's compliance to guideline was significant better between whom with less experience than with long experience.
\end{abstract}

Corresponding author: Email:halashaheen2002@yahoo.com (Hala Shaheen)

\section{Introduction}

World Health Organization define patient safety as "patient's freedom from unnecessary real or potential harm caused by healthcare." Its significance in health care systems all over the world is increasing (1). It defined as "the 
prevention of harm to patients." Emphasis mainly placed on the system of care delivery that (1) prevents errors; (2) learns from the errors that occur; and (3) culture of safety that involves health care professionals, organizations, and patients $^{(2)}$.

Patient safety is a global challenge that requires knowledge and skills in multiple areas, including human factors and systems engineering. The most common errors involved in preventable adverse events were: investigation errors, medication errors, and nosocomial infections ${ }^{(3)}$. Patient safety is a global priority. An estimated $3.7 \%$ to $17.7 \%$ of patients are inadvertent harmed as result of hospital care (4). Some harm caused by healthcare professional error arising from factors such as poor system, equipment design, and high workload ${ }^{(5)}$. Other harm results from deviations from guidelines and policies; as $50-70 \%$ of patients receive recommended care ${ }^{(6)}$. A prerequisite for patient safety is that physicians behave in the interest of their patients. Although practicing safe behavior is an intrinsic part of a physician's ethical and professional standards, physicians practice behaviors that run counter to patient safety ${ }^{(7)}$. Most safety incidents can categorized into four main areas: diagnosis, prescribing, communication between health care providers and patients and organizational issues (i.e. safety climate/ training, even reporting). Significantly, $20 \%$ of errors could have serious consequences ${ }^{(8)}$. Safety culture assessment within healthcare organizations has grown in parallel with the increasing focus on improving safety culture. Also it provides a way of tracking progress in cultural transformation over time. In this way, baseline measures of culture can be taken before and after implementation of a patient safety intervention ${ }^{(9)}$.

Objectives: Identify the frequency of patient safety errors among health care providers in family health centers (HCP) and factors associated with error.

Methods: The study was a cross sectional descriptive one conducted in in El-Ebor family health centers, Qalyubia Governorate, Egypt. All the health care providers in the three family health centers in Elbor city were included in the study. They were total 172 (28 family physicians, 18 Dentists, 36 Pharmacist, 29 Nurses, 9 Social workers and 2 Chemists). Family physician, dentist and pharmacist $(n=123)$ were included in medical job category and the others (49) in paramedical job category. Human rights and ethical considerations were followed during the study, with total confidentiality of any obtained data. The Menoufia Faculty of Medicine Committee for Medical Research Ethics reviewed and formally approved the study before it began. A written consent form was taken from the local health care authorities in the studied centers as well as from all participants after explaining the aim of the study. Each one was personally observed during their job conduction for 15 minutes by the observational checklist. The checklist was used for assessment of the health care provider's commitment to the patient safety measures. It was modified from Egyptian Ministry of Health and Population checklist which is used for a monthly evaluation of primary health care facility. The checklist included personal data as name, age, sex and years of experience. Five dimensions were selected according to their relation to patient safety (1) Patient identification e.g. recording process in tickets and files, (2)The laboratory and pharmacy 
safety measures e.g. condition of prescription, patient education, (3) Infection control measures e.g. gloves wearing and disposal, syringe using and disposal, (4) Health care providers' compliance towards patient safety e.g. written policy, adherence to guidelines in practice, errors recording and correction and (5) Safety climate e.g. leadership in management, discussion of harm safety, error discussion. Observation was conducted for each participant in their work places each for their own rule regarding the provided services. Each item in each dimension was evaluated whether accepted or not accepted, then total score for each dimension was assessed. Total score $\geq$ $60 \%$ denoting accepted safety measures while total score $<60 \%$ denoting unaccepted safety measures.

\section{Statistical management of the collected data:}

Results were collected, tabulated, and statistically analysed using an IBM personal computer and statistical package SPSS version 17(SPSS Inc., Chicago, Illinois, USA). Two types of statistical analyses were carried out; Descriptive statistics, which included number \& percentage, and Analytic statistics that included the $\chi^{2}$-test to study the association between two qualitative variables. $\mathrm{P}$ value less than 0.05 was considered statistically significant.

\section{Results}

This study resulted that $70.9 \%$ of the participants had unaccepted practice regarding patient safety dimensions (figure 1). Nearly half of the health care providers were less than 30 years old
(51.7\%). All age groups had unaccepted patient practice regarding patient safety with no statistical significant difference. The majority of them were females (91\%). Males and females showed unaccepted practice $73.3 \%, 70.7 \%$ respectively. Nearly two thirds of the medical personnel resembling $66.7 \%$ had an unaccepted practice while $81.6 \%$ of the paramedical personnel had unaccepted practice with no statistical significant difference. Regarding accepted practice for patient safety among personnel having more than five years' experience and having five years' experience or less were $43.5 \%$ and $20.9 \%$ respectively with statistical significant difference (table1).

The paramedical groups showed more accepted regarding infection control and patient identification 49\%, 57.1\% respectively than the medical groups $27.6 \%$ and $35.8 \%$ respectively with statistical significant difference. Regarding the different dimensions of patient safety: practice items related to provider compliance with the guidelines as written policy in the health care centers was more accepted among group with five years' experience or less than in the other group with long experience with statistical significant difference. (table 2, 3).

\section{Discussion}

During the last decade issues of patient have come to occupy a prominent position on the political agenda in health care and in several countries systems for incident reporting have been promoted as a have mostly been promoted as means to improved patient safety ${ }^{(10)}$. Addressing errors and the issue of patient safety requires a perspective directed at the human factor involved. It 
is known that to err is human, but, in the health care context, it is necessary for managers, leaders, and professionals to work in appropriate conditions, which minimize the occurrence of errors and of harm to the service users ${ }^{(11)}$. There is a lack of studies published on medical errors in primary care. Many aspects of primary care such as early presentation of undifferentiated disease (12). This study showed that $70.9 \%$ of the participants had unaccepted practice regarding patient safety dimensions on the other hand Sandars and Esmail study ${ }^{(13)}$, conducted a review of 11 studies which were conducted in primary care settings found that the rates of medical errors ranged between 5 and 80 errors per 100,000 visits. Riechers, study (14) reported that the rates of patient incidents in primary care varies as low as 4 and as high as 240000 in 1000000 primary care consultation. The discrepancy between the present study and other studies may be due to conduction of training to health care workers before accreditation without presence of continuous on job training about accreditation dimension including patient safety dimensions.

This study revealed that medical personnel had more accepted practice than the paramedical personnel without statistical significant difference that was in concordance with Abdelhai et al ., ${ }^{(15)}$ study that was conducted in Cairo university hospital and concluded that dimensions of the overall perceptions of safety and frequency of events reporting mean scores were significantly highest for physicians than the_scores of nurses and paramedical personnel. Overall, physicians showed the highest significant positive composite scores while nurses showed the lowest scores in most dimensions.
Patient identification showed significantly more accepted practice among paramedical group than the medical group in the present study. As Abbas (16) reported that the relationship between overall mean scores of the front-line healthcare providers' perceptions toward patient safety and their job categories was statistically significant. On the other hand Carayon (17) study which examined the elements of the work system, employees' outcomes, and care processes by comparing various safety measures applied across three categories: nurses, physicians, and other staff. In their study, they found that there was no difference between the three job categories on the measures of perceptions toward safety performance. As WHO (18) states that the failure to correctly identify patients continues to result in medication errors, transfusion errors, testing errors, wrong person procedures, and the discharge of infants to the wrong families. That is can be explained as in Oliveria etal study (11) which revealed that the principal intervening factors in patient safety related to nursing staff were staff dimensioning and workload, professional qualification and training, team work, being contracted to the institution, turnover and lack of job security, and bad practice/disruptive behaviors. Other studies revealed that membership of a particular professional group influences perceptions of safety climate in the inpatient as well as in the primary care setting, often with more doctors than nurses having positive

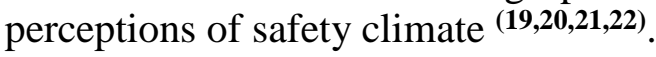

This study revealed a statistically significant difference between the long experience and the provider compliance. Long experience was associated with 
unaccepted practice in provider's compliance to guideline regarding patient safety dimension. As study conducted by Hoffmann ., etal. study ${ }^{(23)}$ which reported that frontline staff were less positive than those of management staff. This finding may indicate the experience of those on the front line differs from that of management because negative information does not always reach managers, thus leading to a different perspective. Studies were conducted in developed nations regarding adherence to infection control guideline showed wide variation in adherence to standard infection control practice guidelines (24, 25,26). Despite abundant supplies, certification requirements, and better monitoring in developed countries, there were only incremental improvements in performance, suggesting that this is a complex, multifactorial problem ${ }^{(27)}$.

\section{Conclusion}

Prevention of medication error and unaccepted practice play important role in improving the patient safety. Paramedical staff had an accepted safety practice regarding patient identification and infection control compared to medical staff. Provider's compliance to guideline was significant better between whom with less experience than with long experience.so continuous medical education and on job training must emphasize training about the different dimensions of patient safety with continuous monitoring for the unaccepted practice with improvement of care.

\section{References}

1) Różańska A , Bulanda $\mathrm{M}$ (2015):.Demographic characteristics of patients and their assessment of selected hygienic practices of hospital personnel in the context of safety climate of hospitalization. Am J Infect Control. 1;43(4):354-7.

2) Donaldson , M S (2008) : Patient Safety and Quality: An EvidenceBased Handbook for Nurses Editor:Ronda G. Hughes, Chapter 3. An Overview of To Err is Human: Re-emphasizing the Message of Patient Safety.page 31.

3) Carayon, $P$ and Wood KE (2010): Patient Safety: The Role of Human Factors and Systems Engineering. CaraStud Health Technol Inform. 153: 23-46.

4) Vincent C, Stanhope N, Crowley-Murphy M (1999): Reasons for not reporting adverse incidents: an empirical study.J Evaluat Clin Prac 5:13-21.

5) -Lawton RJ, McEachan RRC, Giles SJ, Sirriyeh R, Watt IS, Wright J (2012): Development of an evidence-based framework of factors contributing to patient safety incidents in hospital settings: a systematic review. BMJ Quality and Safety 21:369-380.

6) Taylor $N$, Lawton $R$, Slater $B$ and Foy $R$ (2013): The demonstration of a theory-based approach to the design of localized patient safety interventions. Implement Sci.. 8:123.

7) Renkema E, Broekhuis $M$, and Renkema K A (2014): Conditions that influence the impact of malpractice litigation risk on physicians' BMC Health Services Research . 14:38 Page 2.

8) Cox S , Holden J (2007): A retrospective review of significant events reported in one direct in 2004- 2005.Br J Gen Pract 57(542):732-736. 
9) Abdou HA., Saber KM (2011) : A Baseline Assessment of Patient Safety Culture among Nurses at Student University Hospital. World Journal of Medical Sciences 6 (1): 17-26.

10) Kousgaard MB, Joensen AS and Thorsen T (2012): Reasons for not reporting patient safety incidents in general practice: a qualitative study. 30:199-205.

11) Oliveira RM, Leitao IM, Aguiar LL, Oliveira AC, Gazos DM, Silva LM, Barros AA, Sampaio RL. (2015): Evaluating the intervening factors in patient safety: focusing on hospital nursing staff. Rev Esc Enferm USP. ;49(1):104-13.

12) Khoo1 EM, Lee WK, Sararaks S, AbduSamad A, Liew SM, Cheong AT, Ibrahim MY, Su SH, Hanafiah AN, Maskon K , Ismail $R$ and Hamid MA (2012): Medical errors in primary care clinics - a cross sectional study. BMC Family Practice 13:127.

13) Sandars J, Esmail A (2003): The frequency and nature of medical error in primary care: understanding the diversity across studies. Family Practice, 20(3):231-236.

14) Riechers JK, Ospina M, Jonsoon E,Childs P,Mcleod L, Maxted JM (2010): Patient safety in primary care.Candian Patient Safety institute \& BC Patient safety \& quality council. 19-27.

15) Abdelhai R, Abdelaziz SB and Ghanem NS (2012): Assessing Patient Safety Culture and Factors Affecting It among Health Care Providers at Cairo University Hospitals. Journal of American Science ;8(7).

16) Abbas HA, Bassiuni NA, Baddar FM (2008): Perception of front line health care providers towards patient safety : A preliminary Study in a university hospital Egypt. Topics in Advanced Practice Nursing e Journal 8 (2- 11).

17) Carayon P, Alvarado C, Hundt A, Springman S, Borgsdorf A, Hoonakker P. (2003) : An employee questionnaire for assessing patient safety in outpatient surgery. Available at: http://www.ahrq.gov/downloads/pub /advances/vol4/Carayon.pdf Accessed April 1, 2015.

18) WHO Collaborating Centre for Patirent Safety Solutions (2007) : Patient Identification: volume 1, solution 2 .

19) Kho ME, Carbone JM, Lucas J, Cook DJ (2005): Safety Climate Survey: reliability of results from a multicenter ICU survey. Qual Saf Health Care. 14(4):273-278.

20) Huang DT, Clermont G, Sexton JB, et al (2007):. Perceptions of safety culture vary across the intensive care units of a single institution. Crit Care Med. 35(1):165-176.

21) Holden LM, Watts DD, Hinton Walker $P$ (2009): Patient safety climate in primary care: age matters. J Patient Saf. 5(1):23-28.

22) Singer $S$, Lin $S$, Falwell $A$, et al(2009):. Relationship of safety climate and safety performance in hospitals. Health Serv Res. 44(2p1): 399-421.

23) Hoffmann B, Miessner C, Albay $\mathbf{Z}$, Scbrober J, Weppler $\mathbf{K}$, Gerlacb FM(2013): Impact of individual and team features of patient safety climate: Asurvey in family practices. Annals of family medicine vol 11(4):355-62. 
24) Askarian M, Mirzaei K, Mundy LM, McLaws ML.(2005): Assessment of knowledge, attitudes, and practices regarding isolation precautions among Iranian healthcare workers. Infect Control Hosp Epidemiol. 26(1):105-8.

25) Stein AD, Makarawo TP, Ahmad MF.(2003): A survey of doctors' and nurses' knowledge, attitudes and compliance with infection control guidelines in Birmingham teaching hospitals. J Hosp Infect. 54(1):68-73.
26) Gammon J, Morgan-Samuel $H$, Gould D. (2008): A review of the evidence for suboptimal compliance of healthcare practitioners to standard/universal control precautions. J Clin Nurs. 17(2):15767.

27) Cawich $\mathrm{SO}^{1}$, Tennant IA, McGaw CD, Harding H, Walters CA, Crandon IW (2013):Infection control practice in the operating room: staff adherence to existing policies in a developing country. Perm J. 17(3):e114-8. 
Table 1: General characteristics of participants in relation to patient safety dimensions

\begin{tabular}{|c|c|c|c|c|c|c|c|c|}
\hline \multirow{3}{*}{ Parameter } & \multicolumn{4}{|c|}{ Practice acceptability } & \multirow{2}{*}{\multicolumn{2}{|c|}{ Total }} & \multirow{3}{*}{ Chi square } & \multirow{3}{*}{$P$ value } \\
\hline & \multicolumn{2}{|c|}{$\begin{array}{c}\text { unaccepted } \\
\text { practice (122) }\end{array}$} & \multicolumn{2}{|c|}{$\begin{array}{c}\text { Accepted practice } \\
(\mathbf{5 0})\end{array}$} & & & & \\
\hline & No & $\%$ & No & $\%$ & No & $\%$ & & \\
\hline $\begin{aligned} \text { Age } & \\
\bullet & <30 \text { year } \\
\bullet & 30-40 \text { year } \\
\bullet & >40 \text { year }\end{aligned}$ & $\begin{array}{l}62 \\
34 \\
26\end{array}$ & $\begin{array}{l}69.7 \\
66.7 \\
81.3 \\
\end{array}$ & $\begin{array}{c}27 \\
17 \\
6\end{array}$ & $\begin{array}{l}30.3 \\
33.3 \\
18.7\end{array}$ & $\begin{array}{l}89 \\
51 \\
32\end{array}$ & $\begin{array}{l}51.7 \\
29.7 \\
18.6\end{array}$ & 1.43 & $>0.05$ \\
\hline $\begin{array}{ll}\text { Sex } & \\
& \\
\bullet & \text { Male } \\
\text { - } & \text { Female }\end{array}$ & $\begin{array}{c}11 \\
111\end{array}$ & $\begin{array}{l}73.3 \\
70.7\end{array}$ & $\begin{array}{c}4 \\
46\end{array}$ & $\begin{array}{l}26.7 \\
29.3\end{array}$ & $\begin{array}{c}15 \\
157\end{array}$ & $\begin{array}{c}8.7 \\
91.3\end{array}$ & 0.046 & $>0.05$ \\
\hline 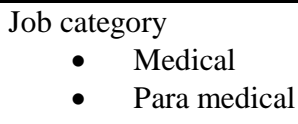 & $\begin{array}{l}82 \\
40\end{array}$ & $\begin{array}{l}66.7 \\
81.6\end{array}$ & $\begin{array}{c}41 \\
9\end{array}$ & $\begin{array}{l}33.3 \\
18.4\end{array}$ & $\begin{array}{c}123 \\
49\end{array}$ & $\begin{array}{l}71.5 \\
28.5\end{array}$ & 3.806 & $>0.05$ \\
\hline $\begin{array}{l}\text { Expérience } \\
\bullet \quad \leq 5 \text { years } \\
\bullet \quad>5 y\end{array}$ & $\begin{array}{l}87 \\
35\end{array}$ & $\begin{array}{l}79.1 \\
56.5\end{array}$ & $\begin{array}{l}23 \\
27\end{array}$ & $\begin{array}{l}20.9 \\
43.5\end{array}$ & $\begin{array}{c}110 \\
62\end{array}$ & $\begin{array}{l}64 \\
36\end{array}$ & 9.856 & $<0.05$ \\
\hline
\end{tabular}

Table 2: Comparison between health care providers regarding job category and acceptability of patient safety dimensions

\begin{tabular}{|c|c|c|c|c|c|c|c|c|}
\hline \multirow{3}{*}{ Patient safety dimension } & \multicolumn{4}{|c|}{ Job category } & \multirow{2}{*}{\multicolumn{2}{|c|}{ Total }} & \multirow{3}{*}{$\begin{array}{l}\text { Chi } \\
\text { square }\end{array}$} & \multirow{3}{*}{$P$ value } \\
\hline & \multicolumn{2}{|c|}{$\begin{array}{l}\text { Medical } \\
\text { category } \\
(123) \\
\end{array}$} & \multicolumn{2}{|c|}{$\begin{array}{l}\text { Paramedical } \\
\text { Category } \\
\text { (49) }\end{array}$} & & & & \\
\hline & No & $\%$ & No & $\%$ & No & 7 & & \\
\hline $\begin{array}{l}\text { Patient identification } \\
\text { - } \quad \text { Accepted } \\
\text { - } \quad \text { Unaccepted }\end{array}$ & $\begin{array}{l}44 \\
79\end{array}$ & $\begin{array}{l}35.8 \\
64,2\end{array}$ & $\begin{array}{l}28 \\
21\end{array}$ & $\begin{array}{l}57.1 \\
42.9\end{array}$ & $\begin{array}{c}72 \\
100\end{array}$ & $\begin{array}{l}41.9 \\
58.1\end{array}$ & 6.575 & $<0.05$ \\
\hline $\begin{array}{c}\text { Lab \& pharmacy services: } \\
\bullet \quad \text { Accepted } \\
\bullet \quad \text { Unaccepted }\end{array}$ & $\begin{array}{l}67 \\
56 \\
\end{array}$ & $\begin{array}{l}54.5 \\
45.5 \\
\end{array}$ & $\begin{array}{l}33 \\
16 \\
\end{array}$ & $\begin{array}{l}63.3 \\
32.7\end{array}$ & $\begin{array}{r}100 \\
72\end{array}$ & $\begin{array}{l}58.1 \\
41.9\end{array}$ & 2.387 & $>0.05$ \\
\hline $\begin{array}{l}\text { Infection control } \\
\text { - } \quad \text { Accepted } \\
\text { - } \quad \text { Unaccepted }\end{array}$ & $\begin{array}{l}34 \\
89\end{array}$ & $\begin{array}{l}27.6 \\
72.4\end{array}$ & $\begin{array}{l}24 \\
25\end{array}$ & $\begin{array}{l}49.0 \\
51.0\end{array}$ & $\begin{array}{c}58 \\
114\end{array}$ & $\begin{array}{l}33.7 \\
66.3\end{array}$ & 7.138 & $<0.05$ \\
\hline $\begin{array}{l}\text { Provider Compliance } \\
\text { - } \quad \text { Accepted } \\
\text { - } \quad \text { Unaccepted }\end{array}$ & $\begin{array}{l}69 \\
54 \\
\end{array}$ & $\begin{array}{l}56.1 \\
43.9\end{array}$ & $\begin{array}{l}31 \\
18 \\
\end{array}$ & $\begin{array}{l}63.3 \\
36.7 \\
\end{array}$ & $\begin{array}{c}100 \\
72 \\
\end{array}$ & $\begin{array}{l}58.1 \\
41.9 \\
\end{array}$ & 0.740 & $>0.05$ \\
\hline $\begin{array}{l}\text { Safety Climate } \\
\text { - } \quad \text { Accepted } \\
\text { - } \quad \text { Unaccepted }\end{array}$ & $\begin{array}{c}14 \\
109\end{array}$ & $\begin{array}{l}11.4 \\
88.6\end{array}$ & $\begin{array}{c}8 \\
41\end{array}$ & $\begin{array}{l}16.3 \\
83.7\end{array}$ & $\begin{array}{c}22 \\
150\end{array}$ & $\begin{array}{l}12.8 \\
87.2\end{array}$ & 0.667 & $>0.05$ \\
\hline
\end{tabular}


Table 3: Comparison between health care providers regarding years of experience and acceptability of patient safety dimensions

\begin{tabular}{|c|c|c|c|c|c|c|c|c|}
\hline \multirow{3}{*}{ Patient safety dimension } & \multicolumn{4}{|c|}{ Duration of experience } & \multirow{2}{*}{\multicolumn{2}{|c|}{ Total }} & \multirow{3}{*}{$\begin{array}{l}\text { Chi } \\
\text { square }\end{array}$} & \multirow{3}{*}{$\begin{array}{l}P \\
\text { value }\end{array}$} \\
\hline & \multicolumn{2}{|c|}{$\leq 5$ years $(110)$} & \multicolumn{2}{|c|}{$>5$ years $(62)$} & & & & \\
\hline & No & $\%$ & No & $\%$ & No & $\%$ & & \\
\hline $\begin{array}{l}\text { Patient identification } \\
\text { - Accepted } \\
\text { - Unaccepted }\end{array}$ & $\begin{array}{l}41 \\
69\end{array}$ & $\begin{array}{l}37.3 \\
62.7\end{array}$ & $\begin{array}{l}31 \\
31\end{array}$ & $\begin{array}{l}50.0 \\
50.0\end{array}$ & $\begin{array}{l}72 \\
100\end{array}$ & $\begin{array}{l}41.9 \\
58.1\end{array}$ & 2.142 & $>0.05$ \\
\hline $\begin{array}{l}\text { Lab \& pharmacy services: } \\
\text { - Accepted } \\
\text { - Unaccepted }\end{array}$ & $\begin{array}{l}68 \\
42 \\
\end{array}$ & $\begin{array}{l}61.8 \\
38.2 \\
\end{array}$ & $\begin{array}{l}32 \\
30 \\
\end{array}$ & $\begin{array}{l}51.6 \\
48.4 \\
\end{array}$ & $\begin{array}{r}100 \\
72 \\
\end{array}$ & $\begin{array}{l}58.1 \\
41.9 \\
\end{array}$ & 1.697 & $>0.05$ \\
\hline $\begin{array}{l}\text { Infection control } \\
\text { - } \quad \text { Accepted } \\
\text { - Unaccepted }\end{array}$ & $\begin{array}{l}33 \\
77\end{array}$ & $\begin{array}{l}30 \\
70\end{array}$ & $\begin{array}{l}25 \\
37\end{array}$ & $\begin{array}{l}40.3 \\
59.7\end{array}$ & $\begin{array}{c}58 \\
114\end{array}$ & $\begin{array}{l}33.7 \\
66.3\end{array}$ & 1.890 & $>0.05$ \\
\hline $\begin{array}{l}\text { Provider Compliance } \\
\text { - Accepted } \\
\text { - Unaccepted }\end{array}$ & $\begin{array}{l}85 \\
25\end{array}$ & $\begin{array}{l}77.3 \\
22.7\end{array}$ & $\begin{array}{l}15 \\
47\end{array}$ & $\begin{array}{l}24.2 \\
75.8\end{array}$ & $\begin{array}{c}100 \\
72\end{array}$ & $\begin{array}{l}41.9 \\
58.1\end{array}$ & 45.902 & $<0.05$ \\
\hline $\begin{array}{l}\text { Safety Climate } \\
\text { - } \quad \text { aAccepted } \\
\text { - } \quad \text { Unaccepted }\end{array}$ & $\begin{array}{l}12 \\
98\end{array}$ & $\begin{array}{l}10.9 \\
98.1\end{array}$ & $\begin{array}{l}10 \\
52\end{array}$ & $\begin{array}{l}16.1 \\
83.9\end{array}$ & $\begin{array}{c}22 \\
150\end{array}$ & $\begin{array}{l}12.8 \\
87.2\end{array}$ & 0.969 & $>0.05$ \\
\hline
\end{tabular}




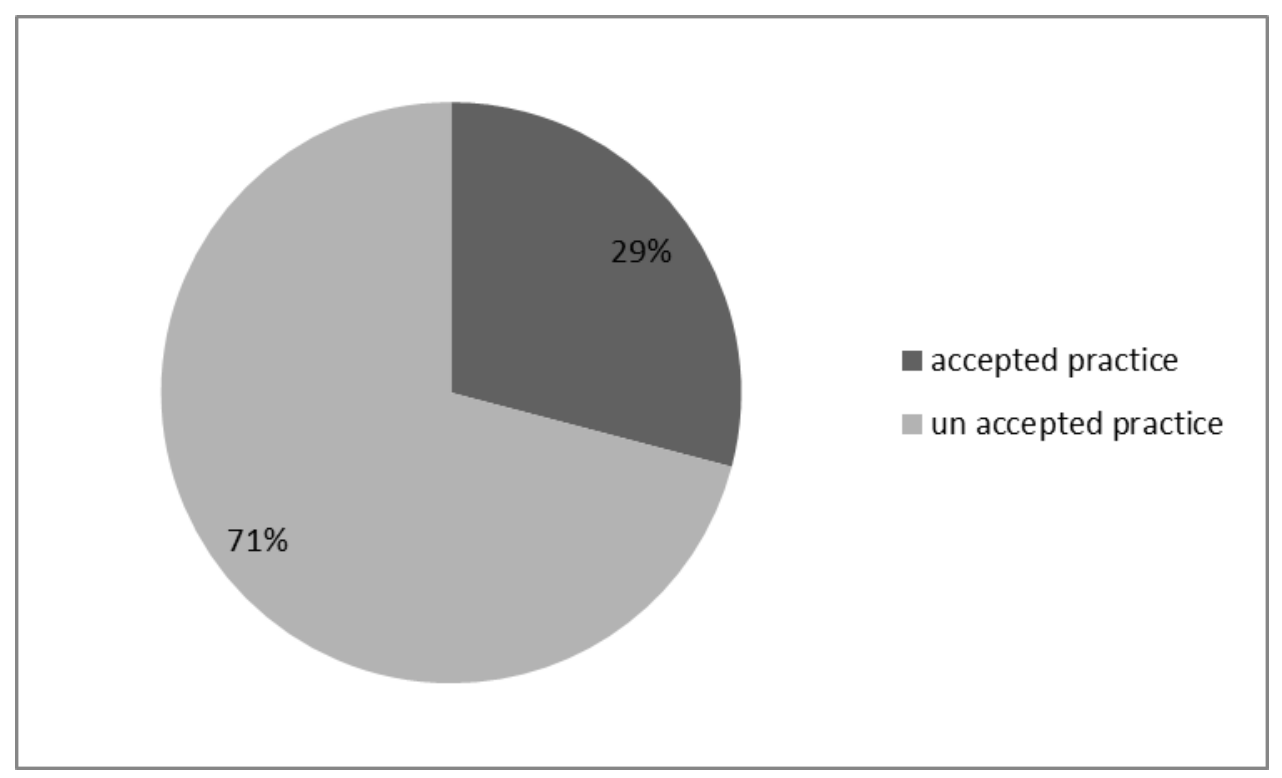

Figure 1: Percentage of accepted and unaccepted practice regarding patient safety among studied participants 